\title{
The Demand For NFL Attendance: A Rational Addiction Model
}

\author{
Erin LeAnne Spenner, Colorado College, USA \\ Aju J. Fenn, Colorado College, USA \\ John R. Crooker, University of Central Missouri, USA
}

\begin{abstract}
This paper examines the demand for attendance at National Football League (NFL) games using a rational addiction model to test the hypothesis that professional football displays the properties of a habit-forming good. Rational addiction theory suggests that past and future consumption play a part in determining the current period's consumption for habit-forming goods. Additionally, we postulate the behavioral implications of profit-maximizing ticket pricing behavior by NFL teams. Previous studies have been unable to detect pricing power by NFL teams. Our model of pricing power allows us to identify theoretically-anticipated pricing behavior. A pooled data set is collected using statistics from each NFL team from the 1983 to the 2008 seasons. Current attendance is modeled as a function of team specific variables, including past and future attendance, ticket price, and team performance. The model is estimated using Two-Stage Least Squares (2SLS). We also treat the censored nature of ticket demand as NFL teams frequently experience sell-outs. It is found that past and future attendance, winning percentage, the age of the stadium in which a team plays, and own-price demand elasticity influence attendance. The fact that coefficients for past and future attendance are positive and significant in this analysis lends support to the notion that NFL fans display characteristics of rational addiction in their consumption behavior. Further, we find evidence to support profit-maximizing behavior in ticket sales.
\end{abstract}

Keywords: sports attendance; rational addiction; NFL demand

\section{INTRODUCTION}

C n 2002, National Football League (NFL) attendance totaled 16,931,340, with an average attendance per game of 66,138. As illustrated in Figure 1, attendance figures have been on the rise since these statistics were first made available. In the NFL, ticket revenues account for nearly one-third of all revenues, making attendance quite important to the league. ${ }^{1}$ Football fans spend substantial amounts of time and money when they attend an NFL game. According to the Fan Cost Index calculated by Team Marketing Report, the average fan spends anywhere from near \$200 in Atlanta to over \$400 in New England when they go to a game. Furthermore, the NFL boasts more fans than any other professional sport in the United States. Over half of all Americans claim to follow the league. Why is it that that the NFL is so popular and why is its popularity growing over time? Is it possible that football fans exhibit characteristics of habit-formation in their behavior? This paper will try to answer such questions by examining NFL attendance using a model of rational addiction.

While addiction is often used to explain a physical dependency on substances, such as alcohol and cigarettes, rational choice theory can explain addictive behavior as it pertains to a much broader array of activities. People can become addicted to any number of things, from food to exercise to work. According to Becker and Murphy (1988), rational addiction theory suggests that people make choices according to their consistent utility maximization plan. This would mean that past consumption and estimated future consumption have an effect on

${ }^{1}$ Rick Horrow, “The NFL Juggernaut at Postseason, Part I,” available from http://cbs.sportsline.com/general/story/7003559, accessed February 1, 2004. 
present consumption for addictive goods. If NFL attendance is habit-forming, then it can be shown that past attendance and estimated future attendance are significant factors that affect present attendance at NFL football games. If, on the other hand, past and estimated future attendance do not affect current attendance, then the notion of habit-formation will be called into question.

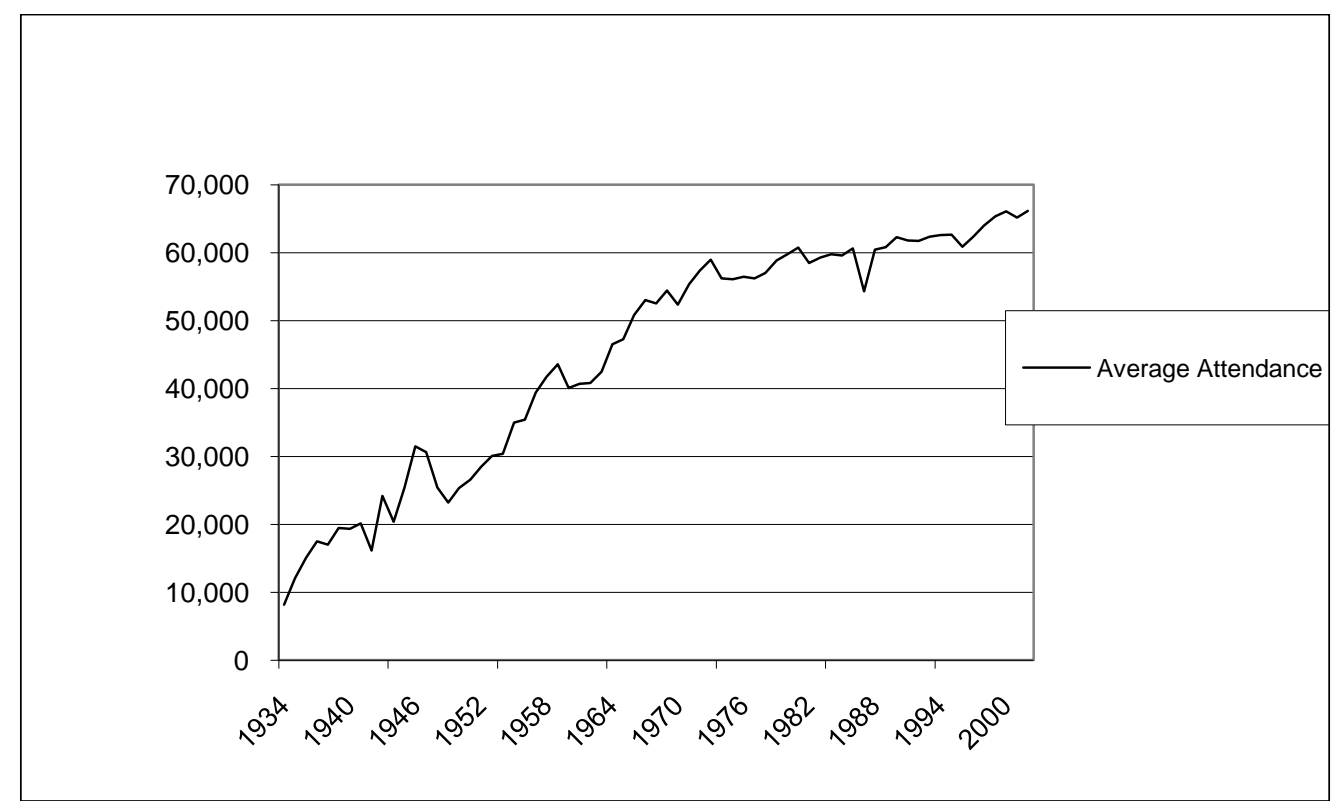

Figure 1: Average NFL Attendance (1934-2002) Source: NFL Record and Fact Book

This paper will proceed as follows. The following section will discuss the relevant literature on the topics of attendance at professional sporting events and the theory of rational addiction. The next section will present the empirical model and methodology. The fourth section will report the results of the regression analysis. The final section will discuss conclusions, along with any caveats encountered, and outline some directions for future research.

\section{CURRENT RESEARCH ON ATTENDANCE AND RATIONAL ADDICTION}

There have been a number of studies in the economics literature on factors that influence the consumption of sports, which is generally represented by spectator attendance at sporting events. Economic demand models have been widely used to analyze the factors that determine spectator attendance, and this method has been applied to various sports. A summary of such literature follows. Downward and Dawson (2000) contains an excellent overview of sports related demand analysis studies.

Baseball attendance has been widely investigated. Kahane and Schmanske (1997) test the proposition that roster turnover has an impact on MLB attendance. Using data from the 1990 through 1992 MLB seasons and an ordinary least squares estimator, they find that turnover does indeed have a significant and negative impact on attendance in MLB. In another study on Major League Baseball attendance, McDonald and Rascher (2000) explore the effects that special promotions have on game day attendance. Using ordinary least squares regression, they find that promotions increase game-day attendance by about $14 \%$. Other studies on demand for baseball attendance include Boyd (2003), which also examines the impact of promotions, Rivers and DeSchriver (2002), which examines the impact of star players, Schmidt and Berri (2002), which examines the impact of strikes, and Schmidt and Berri (2001), which examines how competitive balance influences attendance. 
There have also been some studies on attendance at basketball games. Burdekin and Idson (1991) examine the effect that customer discrimination has on attendance for the National Basketball Association (NBA). They find that attendance is significantly affected by the racial composition of the team relative to the racial composition of the market area. Zhang, Pease, Hui, and Michaud (1995) explore the variables that determine whether or not spectators will attend NBA games by developing the Spectator Decision Making Inventory. Using a survey of a random sample of 861 NBA spectators, that they find that game promotion, home team, opposing team, and schedule convenience are significantly related to game attendance. Berri, Schmidt, and Brook (2004) examine the impact of star players on NBA attendance, finding that the functional form of the regression equation affects whether or not star players have a significant impact on the demand for attendance.

Soccer is another sport that has been relatively well studied. Peel and Thomas (1988) investigate the determinants of attendance for professional soccer in England, hypothesizing that games that are not predicable attract bigger crowds. Using data from the 1981-82 season of the English Football League, they find that economic, geographic, and demographic variables play a part in determining attendance at soccer matches. Baimbridge (1997) examines soccer match attendance at the European Championship that was held in England in 1996. He uses ordinary least squares regression and finds that the distance between the team's home city and the tournament site and the quality of the teams are the most important factors that affect tournament attendance. Recent studies on attendance at soccer matches include Hall (2004), which examines the role that television plays in determining attendance, and Szymanski (2001), which examines the relationship between financial parity, competitive balance, and attendance at English soccer matches.

As for football, there have been studies done in recent years on the demand for attendance at collegiate as well as professional football games. In their study of NCAA Division II football, DeSchriver and Jensen (2002) examine the relationship between attendance at college football games and various economic and game variables. Results of the analysis suggest that both the past season and current season winning percentages have an affect on attendance, with the past season's performance becoming relatively less important than the current season's performance as the season progresses. Promotional activities, size of the college, and competition within the market were also found to be significant factors in determining attendance at college football games. A similar study on Division I college football was conducted by Price and Sen (2003). Welki and Zlatoper (1994) examine NFL attendance and the factors that affect it. The regression analysis indicates that the home team's winning percentage is an important factor in determining attendance. They also suggest that higher ticket prices depress attendance and that the demand for professional football appears to be inelastic.

These studies provide a solid foundation for research on NFL attendance, but none of the studies attempt to account for habit-formation in their models. Economic theory regarding the role that habits play in the demand for goods is a relatively new subject. Alfred Marshall initially mentioned the idea in his 1920 textbook. Marshall notes:

... whether a commodity conforms to the law of diminishing or increasing return, the increase in consumption resulting from a fall in price is gradual; and, further, habits which have once grown up around the use of a commodity while its price is low are not quickly abandoned when its price rises again.

Recently, attempts have been made to integrate habit-formation with economic theory. For a comprehensive review of addiction literature see Fenn (1998) and Chaloupka (1988). This study will focus on rational addiction theory as it applies to a demand model for the NFL. It will rely on the work of Fenn (1998), which follows seminal theoretical work by Becker and Murphy (1988) and empirical work by Becker, Grossman, and Murphy (1994).

Rational addiction, according to Becker and Murphy (1988), implies that people make choices according to their consistent utility maximization plan. Their theoretical work outlines the demand model for a habit-forming good, which includes price, past consumption, and expected future consumption. Future empirical work by the likes of Chaloupka (1991), Grossman (1993), Becker, Grossman, and Murphy (1994), and Fenn, Antonovitz, and Schroeter (2001) find support for the rational addiction model in the case of goods with known habit-forming properties such as cigarettes and alcohol. 
As for sports attendance and habit-formation, there has been limited investigation. Ahn and Lee (2003) attempt to apply elements of the rational addiction model to sports consumption in their examination of baseball attendance. The results of their regression analysis indicate that baseball consumption is indeed habitual, but not necessarily addictive in the rational sense (i.e. past consumption influences present consumption but future consumption is insignificant). Byers, Peel, and Thomas (2000) analyze the possibility of rational habit-formation among professional soccer fans in England. The results indicate support for the rational habit-formation model, suggesting that habit may be an important factor that influences spectators at professional sporting events.

Another body of literature accounts for habit-formation by including a measure of "fan loyalty" in the demand equation. While these models are not models of rational addiction, they do consider habit as a factor in the demand for attendance. One such example is found in Dobson and Goddard (1995), which examines attendance in the English Football League. They employ two-stage least squares (2SLS), where attendance and loyalty are endogenous variables, and find that team success, price, and loyalty are significant factors that determine attendance at soccer matches in England.

The present study will fuse elements from the body of literature on attendance at sporting events with the current research on rational addiction. Following the earlier work done on attendance, this study will examine the traditional variables used in predicting spectatorship at sporting events to see how they impact NFL attendance. Estimated past and future consumption are added to the model, according to rational addiction theory. The result will be a model that accounts for habit formation in the demand for attendance at NFL games. The following section will outline this model and discuss the data.

\section{MODEL AND DATA}

The empirical model will be tested using a pooled data set that has been collected from every team in the National Football League for the 1983 through 2008 NFL seasons. There are a total of 32 NFL teams that play 16 games each regular season, which does not include pre-season or playoff games. Due to the requirements of the rational addiction model that will be discussed later in this paper, each team used in the data set had to play at least three seasons to provide sufficient data for one observation. ${ }^{2}$ This result is a pooled data set comprised of annual statistics from thirty-one teams. There are three expansion teams in this set that will be discussed in the following subsection. The remaining 28 teams existed for all 17 seasons. This yields a total of 764 observations. Annual data was collected for each team and its respective city.

Given the pooled dataset, the trade-off we face in using the data to estimate the demand for ticket attendance is that we impose a similar preference structure across teams. Ideally, we would estimate team specific demands allowing for divergent fan preferences in the varying NFL markets. This is not feasible as we lack enough observations to appropriately identify the market specific demand for NFL attendance. At least, the gains by pooling the data allow for us to explore the implications of stadium capacity on demand estimation. With this said, we do control for some individual team effects (as shift factors in the demand) in the instrumental variable regression presented below.

Profit maximization is modeled as follows. Given that the stadium has fixed capacity in a particular year, the team has no marginal cost of a fan attending up to the capacity constraint. Once the capacity constraint is reached, the marginal cost is infinite. This implies that the team will maximize profits by maximizing ticket revenue in a given season (a point that is emphasized below). Ticket revenue is maximized when the elasticity of demand is unit elastic. Figure 2 indicates the optimal price for tickets given the demand curve $\mathrm{D}$ in a stadium with no binding capacity constraint. The price $\mathrm{p}$ corresponds to the point on the demand curve where demand is unit elastic.

\footnotetext{
${ }^{2}$ The Houston Texans franchise had to be eliminated from the data set since they were a new expansion team in 2002 and only one season of data was available.
} 


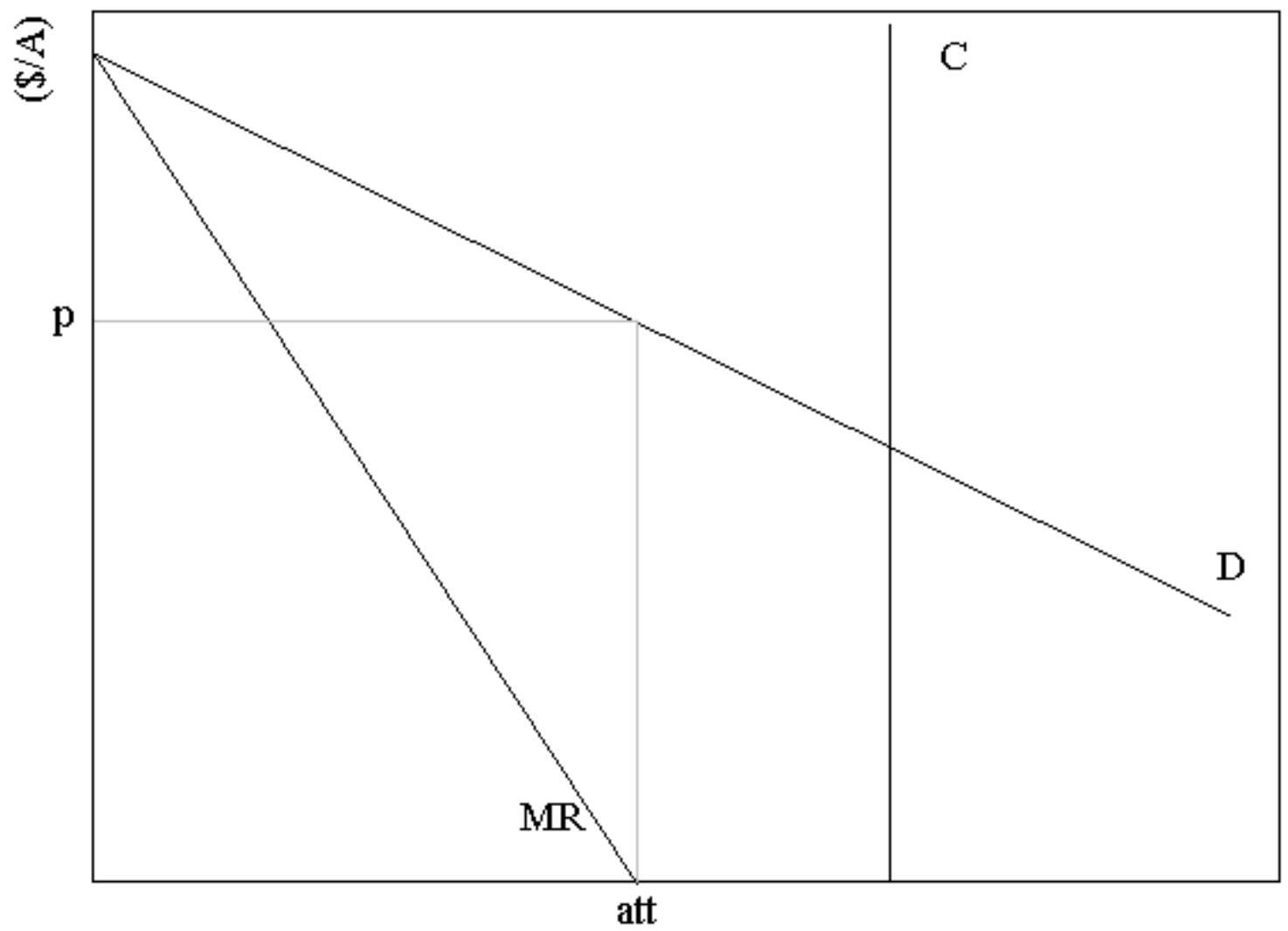

Attendance

Figure 2: Optimal Ticket Price with No Capacity Constraint

Teams may adjust the capacity of the stadiums in which they operate between seasons. As profit maximizers, the team will adjust capacity upwards to capture profits. This suggests that capacity is endogenous (many teams adjust stadium capacity throughout our time series). We can detect capacity constraining profits when season attendance for a particular team falls on the elastic portion of the demand curve. Figure 3 indicates the optimal price for tickets given the demand curve $\mathrm{D}$ in a stadium with a binding capacity constraint. Notice that the price that maximizes profits is the height of the demand curve where marginal revenue (MR) hits the horizontal axis. Yet, the stadium lacks the capacity to admit the number of fans necessary to maximize profits. So, the team does the best it can in the short-run by charging the highest price the market will bear at the capacity constraint. This is the price indicated by $\mathrm{p}$. In the long-run, the team will choose to add to capacity. We expect to observe falling ticket prices and rising attendance as team bring the extra capacity over time-holding everything else constant.

Mathematically, we are suggesting profits over a season are given by

$\pi=R_{0}+P($ att $)$ att $-C_{0}$,

where $\pi$ is profits, $R_{0}$ is non-attendance sources of revenue, $\mathrm{P}(\mathrm{att})$ is the team's price as a function of expected attendance, att is fan attendance, and $C_{0}$ is total cost. To maximize profits, the team's first-order condition is

$\frac{\partial P}{\partial a t t} a t t+P=0 . \leftrightarrow \frac{\partial P}{\partial a t t} \frac{a t t}{P}+1=0 \leftrightarrow\left|E_{d}\right|=1$. 


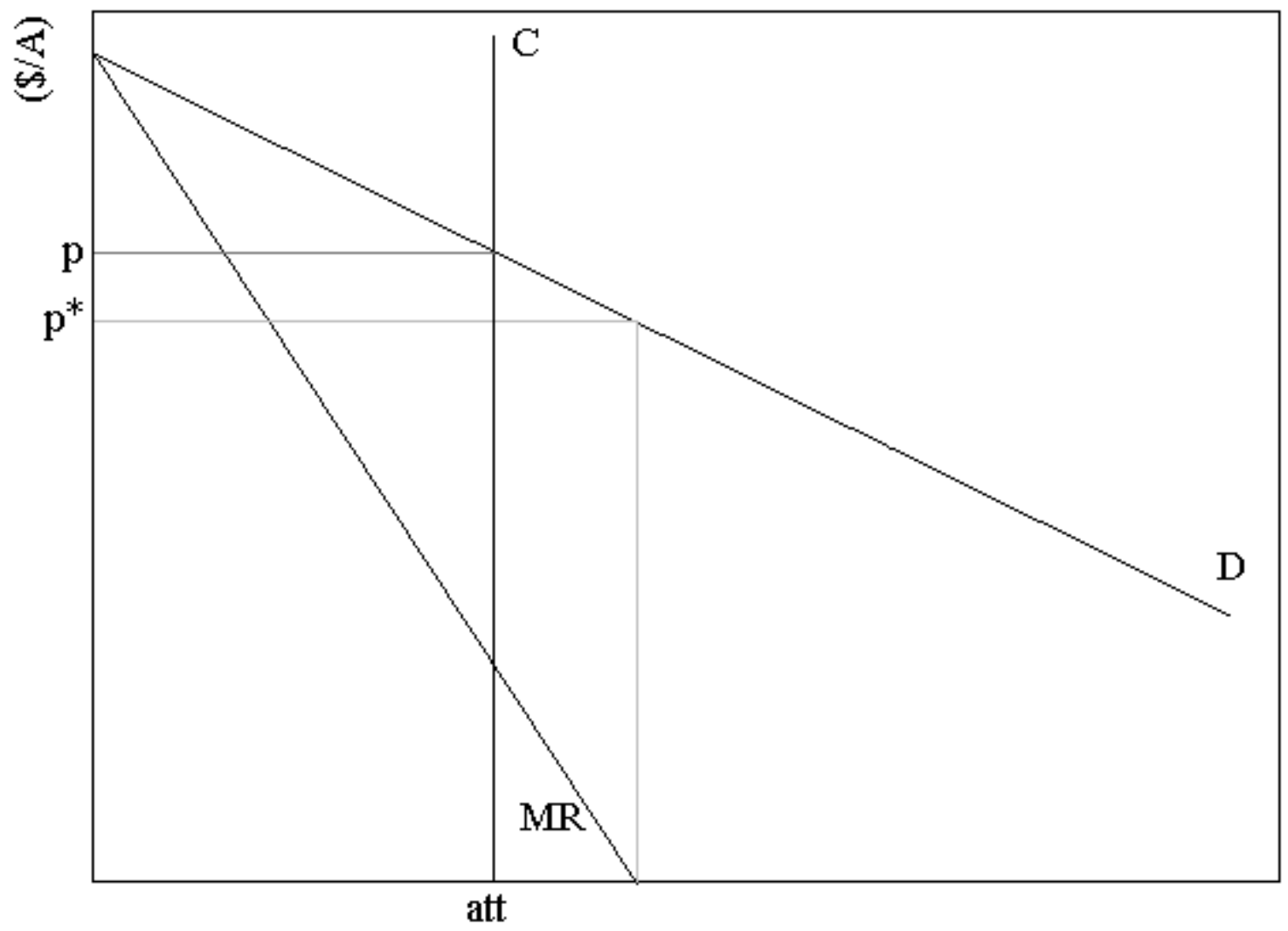

Attendance

Figure 3: Optimal Ticket Price given a Capacity Constraint

This suggests that over time we anticipate the own-price elasticity of demand to tend to 1 . If the elasticity of demand is less than 1 , teams will raise ticket price. If the elasticity of demand is greater than 1 , teams will add to capacity and/or lower ticket prices. This is the structural implication of profit maximization. Given capacity is costly to add over time, team do not desire excessive capacity. Hence, we anticipate the team's forecast of the sensitivity of ticket demand to changes in the price is

$c \equiv\left|\frac{\partial a t t}{\partial P}\right|=\frac{\text { Capacity }}{P}$,

where Capacity is the stadium capacity for the year. Profit maximization occurs when ticket demand is exactly at capacity, elasticity of demand is unitary, and the team has no costly excessive capacity.

For our observed data, $75 \%$ of our observations have excess capacity below $13.28 \%$ (the histogram of excess capacity is provided in Figure 4). This suggests that the variable we have defined as $c$ immediately above serves as a useful proxy for the team's forecast of the sensitivity of fans to changes in ticket price. Furthermore, we use this proxy as an independent variable in explaining attendance. This proxy will be useful in explaining attendance because it captures the time dynamic of how team respond optimally to attendance trends by setting price. For example, if price was set too high last period (or the team is constrained by stadium capacity), the ownprice elasticity of demand last period would be larger than 1. As we have demonstrated above, the profit maximizing team would decrease ticket price in the subsequent time period while simultaneously increasing stadium capacity. If price was set too low last period, the own-price elasticity of demand would be smaller than 1 . The 
profit maximizing team would increase ticket price in this setting. The failure to account for this dynamic pricing interaction between fans and teams over time may be one reason past studies have found ticket prices to be insignificant or positively related to attendance.

\section{Figure 4: Histogram of xCap}

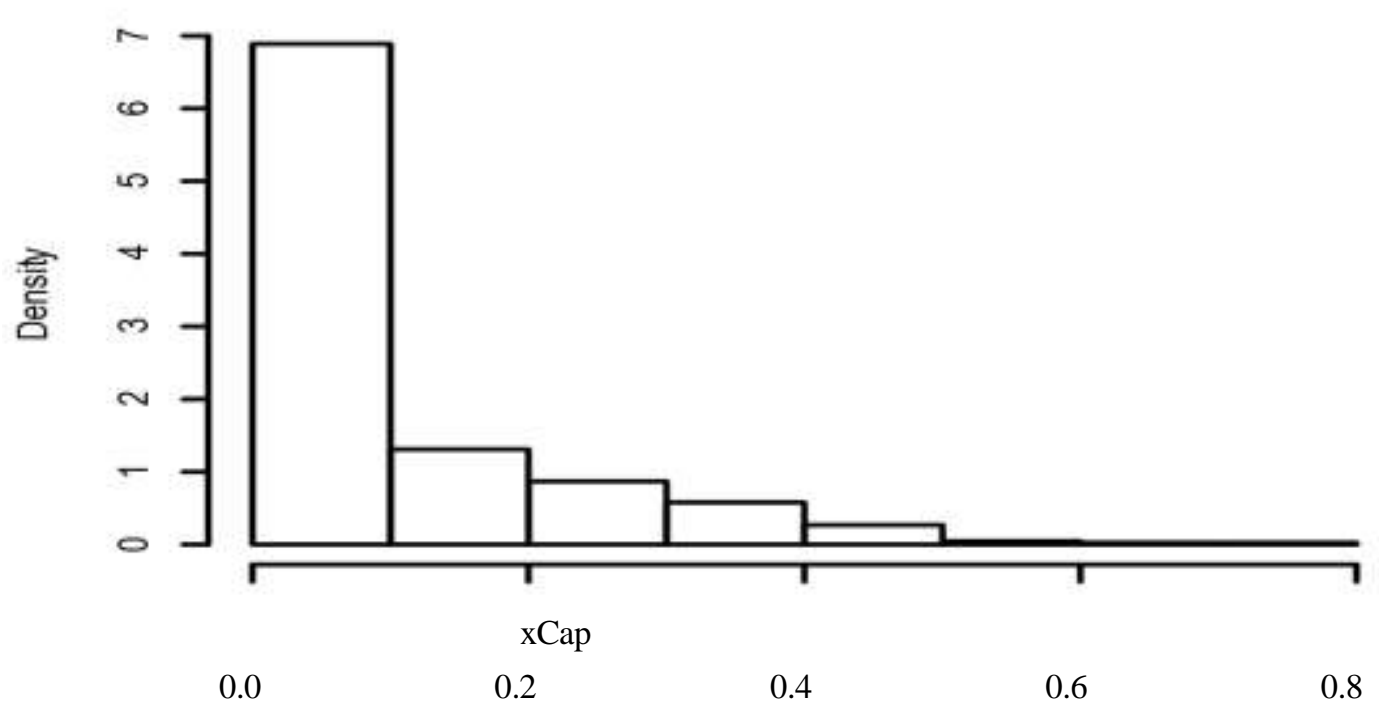

As some teams play in stadiums with excess capacity, the ratio of stadium capacity to ticket price fails to serve a useful proxy for $c$, defined above. To identify when this occurs, we define a dummy variable, TOOBIG, to take on the value 1 when excess capacity is over 5\%. Next, we define the lagged Elasticity of Demand as

$$
E_{d}=\left|c \frac{P_{t-1}}{a t t_{t-1}}\right|
$$

We then create the interaction variable $E_{d}(1-T O O B I G)$. So, if $c$ is serving as a useful proxy, we use the own-price elasticity of demand to capture the price interaction between fans and teams. If, on the other hand, $c$ is not serving as a useful proxy, we capture the demand implications in the coefficient on the TOOBIG dummy. We anticipate that the estimated coefficient on the interaction variable will be positive, reflecting the optimal price/capacity response of the team to last periods own-price elasticity of demand. The basic empirical model is displayed in equation 5 .

$a t t_{t}=b_{0}+b_{1} a t t_{t-1}+b_{2} a t t_{t+1}+b_{3} E_{d, t-1}\left(1-\right.$ TOOBIG $\left._{t}\right)+b_{4}$ TOOBIG $_{t}+b_{5}$ WINPCT $_{t}+e_{t}$

Table 1 provides a brief description of each of the variables in the regression equation, along with the mean and standard deviation of each of the variables.

Table 1: Variable Definitions and Descriptive Statistics

\begin{tabular}{|l|l|c|}
\hline \multicolumn{1}{|c|}{ Variable } & \multicolumn{1}{|c|}{ Description } & Mean \\
\hline att $_{\mathrm{t}}$ & Total annual attendance for each NFL team from the NFL Record and Fact Book & 489968 \\
\hline $\mathrm{E}_{\mathrm{d}}$ & Own-price elasticity of Demand & 1.11 \\
\hline $\mathrm{P}_{\mathrm{t}}$ & Weighted average annual ticket price for each team each year & 38.55 \\
\hline WINPCT $_{\mathrm{t}}$ & Team winning percentage for each season & 0.50 \\
\hline TOOBIG $_{\mathrm{t}}$ & A dummy variable indicating if the team has more than 5\% excess stadium capacity & 0.41 \\
\hline
\end{tabular}


There are two key complications with estimating equation (5) using ordinary least squares. First, the future value of attendance is included as a explanatory variable. Second, as we explain below, ticket demand is actually right-tail censored. This is because we only observe ticket demand when ticket demand is less than or equal to stadium capacity.

Given future attendance is stochastic and correlated with the current stochastic portion of attendance $e_{t}$, the exogeneity condition for ordinary least squares is violated. To overcome this violation, we use an instrumental variables approach to first forecast future attendance with non-stochastic instruments. Once this is done, we use the forecasted future attendance in place of future attendance in equation 5. The instrumental variables regression for future attendance is:

$$
\begin{aligned}
& \text { att }_{t+1}=a_{0}+a_{1} \text { Capacity }_{t}+a_{2} \text { STADAGE }_{t}+a_{3} \text { Income }_{t}+a_{4} \text { ALLSTARS }_{t}+a_{5} \text { NUMPROTMS }_{t}+a_{6} \text { DAZ }_{T}+ \\
& a_{7} D A T_{t}+a_{8} D B U F_{t}+a_{9} D C A R_{t}+a_{10} D C H I C_{t}+a_{11} D C_{1} N_{t}+a_{12} D D A L_{t}+a_{13} D D E N_{t}+a_{14} D D E T_{t}+ \\
& a_{15} D_{\text {DG }}+a_{16} \text { DOILTITAN }_{t}+a_{17} \text { DINDY }_{t}+a_{18} D J A C K_{t}+a_{19} \text { DLARAMS }+a_{20} \text { DMIAMI }_{t}+a_{21} \text { DMIN }_{t}+ \\
& a_{22} D N E_{t}+a_{23} D N O_{t}+a_{24} D_{G N T S_{t}}+a_{25} \text { DNYJTS }_{t}+a_{26} D O A K_{t}+a_{27} D P H I L L Y_{28}+a_{28} D P I T_{t}+a_{29} D S D_{t}+ \\
& a_{30} D S F_{t}+a_{31} D S E A_{t}+a_{32} D T B_{t}+a_{33} X 83_{t}+a_{34} X 84_{t}+a_{35} X 85_{t}+a_{36} X 86_{t}+a_{37} X 87_{t}+a_{38} X 88_{t}+ \\
& a_{39} X 89_{t}+a_{40} X 90_{t}+a_{41} X 91_{t}+a_{42} X 92_{t}+a_{43} X 93_{t}+a_{44} X 94_{t}+a_{45} X 95_{t}+a_{46} X 96_{t}+a_{47} X 97_{t}+ \\
& a_{48} X 98_{t}+a_{49} X 99_{t}+a_{50} X 00_{t}+e_{F, t}
\end{aligned}
$$

The instrument variables, included as explanatory variables for future attendance, are defined below in the independent variables and dummy variables sections.

The issue of truncated ticket demand is discussed and treated in the section on Tobit estimation later on in the paper. The truncation requires the adoption of a maximum likelihood estimation technique to recover the model parameters of interest.

\section{Relocation and Expansion Teams}

Some of the teams included in the data set are expansion teams that entered the league at some point during the 1983 through 2008 period. Both the Carolina Panthers and the Jacksonville Jaguars entered the NFL in 1995. Also, the Cleveland Browns left Cleveland to become the Baltimore Ravens in 1996. Then, in 1999, Cleveland was granted an expansion team, still called the Browns, to replace the Browns that had left town three years before. These three teams are the only examples of expansion teams that entered the league during the time period that is being studied. Since the data is broken down by team and by year, the fact that these teams did not exist for the entire data set was not problematic econometrically. The expansion teams were simply included in the data set as any other team, except for the fact that significantly fewer observations were available for these three teams.

There were also a number of teams that relocated during the time period of interest. The Oakland Raiders, who began playing in Oakland in 1970, relocated to Los Angeles in 1982. The franchise then packed up and moved back to Oakland in 1995. Also, the Titans that now play in Tennessee called Houston home from 1970 through 1996. The Rams have been playing in St. Louis since 1995, after they followed the Raiders lead and left the City of Angels. Also, as previously discussed, the Ravens that now play in Baltimore were the Cleveland Browns until 1996. In calculating the demographic variables such as income and city-specific variables such as number of professional teams, great care had to be taken to ensure that the information was being calculated for the correct cities when teams relocated.

\section{Dependent Variable}

The dependent variable, $a t t_{t}$ from equation 5 , in the empirical model will be attendance. This is measured for each NFL team for each season as total paid attendance. The data was collected from the NFL Record and Fact Book, published for every season from 1983 through $2008 .^{3}$

\footnotetext{
${ }^{3}$ A special thank you is owed to Kenn Tomasch, Rod Fort, and Alexander Hinojos for their work to help ensure the integrity and accuracy of this data set.
} 


\section{Independent Variables}

The independent variables that will be used are mostly team-specific variables. The first team-specific explanatory variable is ticket price, $P_{t}$ from equations 3 and 4 , which is defined as the average ticket price for each team for each year. The ticket price used is a weighted average, attained by accounting for the number of seats at each specific ticket price in calculating the average price for each team in a given year. This data was also collected from Rod Fort's Sports Business Data Pages and then deflated by the Consumer Price Index to generate real prices. ${ }^{4}$ Ticket price, according to the law of demand, should be negatively related to the quantity demanded of NFL games. Depending upon the elasticity of demand for the good, demand may be more or less sensitive to changes in price, but price is expected to have some negative impact. As described above, we anticipate observing the price effect in coefficient $b_{3}$ from equation (5).

The next explanatory variable is winning percentage, WINPCT $_{t}$ in equation 5 , which is the winning percentage of each team for each season included in the data set. This is calculated by dividing the total number of regular season wins by the total number of regular season games. In the event of a tie, which is a possibility in the NFL, each team was given one-half of a win. Winning percentage was calculated using statistics from Total football II: The encyclopedia of the national football league. According to past studies, such as Welki and Zlatoper (1994), DeSchriver and Jensen (2002), and Price and Sen (2003), winning percentage is expected to have a positive effect on attendance. It seems that winning teams tend to create greater interest and draw in bigger crowds in most cases.

The variables TOOBIG $\mathrm{t}_{\mathrm{t}}$ and $\mathrm{E}_{\mathrm{d}}$ are defined in the previous section. TOOBIG $\mathrm{T}_{\mathrm{t}}$ is a dummy variable that indicates when a team has more than $5 \%$ in excess stadium capacity. We include this variable in the model as it indicates when the ratio of stadium capacity to ticket price serves as a useful proxy for the sensitivity of demand for tickets to changes in ticket price. When TOOBIG $_{t}$ takes on the value of 1 , the ratio of stadium capacity to ticket price will fail to proxy the sensitivity of demand for tickets to ticket price as detailed above. $E_{d}$ is the lagged value of own-price elasticity of demand. As we suggest above, this variable will be accurately measured when excess capacity is small or 0 given NFL teams are profit maximizers. Notice that equation (5) includes the interaction of $\left(1-\mathrm{TOOBIG}_{t}\right)$ and $\mathrm{E}_{\mathrm{d}}$. Thus, the coefficient $\mathrm{b}_{3}$ only measures the price effect when we anticipate $\mathrm{E}_{\mathrm{d}}$ to be reasonably measured. The coefficient $b_{4}$ will capture the implications for attendance when $E_{d}$ is not reasonably measured.

Stadium age, stadage ${ }_{t}$ in equation 1 , is another variable that appears on the right-hand side of the regression equation. This is the age, in years, of the facility in which each NFL team plays in any given season. When a new stadium is built or an old stadium is significantly renovated, the stadium age variable will have the value of one for the first season during which the stadium is used. The stadium age variable will take on a value of two in the following season, three in the next, and so on until the team moves to a new stadium or the old one is substantially renovated. Then, the variable starts over at one. These ages were calculated using information from the NFL Record and Fact Books. The age of the facility in which the team plays is expected to impact the demand for attendance negatively. Previous studies, such as Howard and Cromton (2003) and Kahane and Schmanske (1997), have explored the stadium novelty effect, finding that newer stadiums tend to boost attendance. Empirical evidence suggests that although the novelty effect loses much of its power after the first year or two with attendances often falling in subsequent years, the overall impact is still seen for many years afterward since attendances rarely drop below the figures seen before the stadium was built. Thus, older stadiums are expected to be associated with lower attendance figures.

Income, displayed as income $_{t}$ in equation 1 , is also a variable that is used to explain attendance. In the empirical model, per capita income for the Metropolitan Statistical Area is used. These data were obtained from the website of the Bureau of Economic Analysis and are also adjusted for inflation by dividing the series by the Consumer Price Index for all urban consumers series whose base year is 1983. As was noted in a previous subsection, certain NFL teams have not played in the same city each year. Care had to be taken in matching the correct Metropolitan Statistical Area with the correct team for each season. Per capita income figures were gathered for the city in which the team played in any given season, even when it was not the same city that hosted the team the

\footnotetext{
${ }^{4}$ The Consumer Price Index was taken from the U.S. Department of Labor. All values were calculated in terms of 1983 dollars.
} 
previous season. Income is an important factor in the demand for any good, with higher income causing increased consumption for normal goods. However, it is unclear whether or not professional sporting events are normal goods with some studies, such as Noll (1974) and Welki and Zlatoper (1994), finding the impact of increased income to be negative or insignificant. Therefore, the expected sign and perhaps the significance of the income coefficient are uncertain.

The number of professional sports teams in each city that houses an NFL team was also expected to have some impact on the attendance of professional football games in that city. Therefore, the total number of professional football, basketball, hockey, and baseball teams that are in an NFL city is included as an explanatory variable. This variable is named numprotms $s_{t}$ in equation 1 . It was constructed using team information that is included on each league's website. The number of other professional sports teams in the city could have a negative impact on attendance, since they could be seen as substitutes for NFL teams. Noll (1974) found this to be the case for professional baseball. However, the other teams could also be viewed as complementary goods and could thus increase the demand for NFL attendance. The sign of this variable is ambiguous.

The number of marquis players on a team is included as a variable that may have an effect on the attendance for that team and is shown as allstars $s_{t}$ in equation 1. The number of players that a team sends to the Pro Bowl in a given season is used as a proxy for such talent. Pro Bowl rosters for each year were found at pro-footballreference.com. The number of Pro Bowl players is expected to have a positive impact on attendance, since bigname superstars often attract crowds. However, Rivers and DeSchriver (2002) found that star players only seemed to increase attendance at Major League Baseball games when their presence on the team was accompanied by an improvement in team performance. It is unclear whether or not this variable will be significant.

\section{Dummy Variables}

In addition to the TOOBIG dummy defined and discussed above, we allow for team specific and year dummy variables. The team specific dummy variables include DAZ, DAT, DBUF, DCAR, DCHIC, DCIN, DDAL, DDEN, DDET, DGB, DOILTITAN, DINDY, DJACK, DLARAMS, DMIAMI, DMIN, DNE, DNO, DGNTS, DNYJTS, DOAK, DPHILLY, DPIT, DSD, DSF, DSEA, and DTB. These variables correspond to Arizona, Atlanta, Buffalo, Carolina, Chicago, Cincinnati, Dallas, Denver, Detroit, Green Bay, Tennessee, Indianapolis, Jacksonville, St. Louis, Miami, Minnesota, New England, New Orleans, New York Giants, New York Jets, Oakland, Philadelphia, Pittsburgh, San Diego, San Francisco, Seattle, and Tampa Bay. We also include the year specific dummy variables X83, X84, X85, X86, X87, X88, X89, X89, X90, X91, X92, X93, X94, X95, X96, X97, X98, $\mathrm{X} 99, \mathrm{X} 00, \mathrm{X} 01, \mathrm{X} 02, \mathrm{X} 03, \mathrm{X} 04, \mathrm{X} 05, \mathrm{X} 06, \mathrm{X} 07$ and X08. These year dummy variables correspond to data from the years 1983 through 2008, respectively. The signs of the coefficients on the dummy variables are unknown and are expected to vary across teams and over time.

\section{Past and Future Attendance}

Recall that appearing on the right-hand side of regression equation 5 are past and future attendance variables, $a t t_{t-1}$ and $a t_{t+1}$, respectively. According to rational addiction theory, past and expected future consumption have an impact on present consumption for habit-forming goods. Thus, if the NFL is indeed habit-forming, then the coefficients associated with past and future attendance should be positive and significant. A complete derivation of the demand function for a 'good' with habit-forming properties can be found in the Appendix, providing justification for the inclusion of past and future attendance in the regression model.

\section{Estimation Procedures}

To estimate the demand for NFL attendance, fixed-effects two-stage least squares (FE2SLS) will be employed. This estimation procedure was chosen due to the fact that actual figures for past and future attendance $a t t_{t-1}$ and att $_{t+1}$, respectively, are endogenous in the regression equation because they would each depend on present attendance according to the model. The method of FE2SLS involves using instrumental variables to run a first stage regression with future attendance as the dependent variable. This regression corresponds to equation (6) above. The predicted values obtained from this first stage regression for future attendance is then used in the second stage as an 
independent variable to explain the current period's attendance, att in equation 5. Using the predicted values instead of actual values remedies the econometric problems associated with having independent variables that are correlated with the error term. The instrumental variables that were used in the first stage of regressions are presented in Table 2.

Table 2: Two-Stage Least Squares Instrumental Variables and Definitions

\begin{tabular}{|l|l|}
\hline \multicolumn{1}{|c|}{ Variable Name } & \multicolumn{1}{c|}{ Description } \\
\hline Capacity & Stadium capacity for the current season. \\
\hline ALLSTARS & The number of All-Stars on the team's roster for the current season. \\
\hline winpct $_{\mathrm{t}}$ & Team winning percentage for the current season \\
\hline NUMPROTMS & The number of promotional events sponsored during home games throughout the current season. \\
\hline stadage $_{\mathrm{t}}$ & Age of the facility in which the team played in for the current season \\
\hline income $_{\mathrm{t}}$ & Annual per capita metropolitan statistical area income for the previous year \\
\hline $\mathrm{D}$ & Team specific dummy variables. \\
\hline $\mathrm{X}$ & Year specific dummy variables. \\
\hline
\end{tabular}

\section{REGRESSION RESULTS}

Table 3 summarizes the results of the regression analyses from the instrumental variable model that was estimated to predict future attendance. The coefficients and t-statistics on team specific and annual time dummies have not been reported in order to save space. With the predicted future attendance variable formed, we may now estimate equation 6. To do so requires a formal treatment of the censored ticket demand. This is the goal of the next section.

Table 3: Instrument Variable Predictions of Future Attendance

\begin{tabular}{|l|c|c|}
\hline \multicolumn{1}{|c|}{ Variable } & Coefficient & T-value \\
\hline (Intercept) & 229500 & 4.292 \\
\hline Capacity & 0.5109 & 9.928 \\
\hline STADAGE & -972.6 & -4.251 \\
\hline Income & -0.4482 & -0.45 \\
\hline ALLSTARS & 3462 & 3.905 \\
\hline NUMPROTMS & -439.9 & -0.17 \\
\hline
\end{tabular}

\section{ESTIMATION OF CENSORED ATTENDANCE MODEL}

As detailed above, we use an instrumental variables approach to forecast the future value of attendance. The results of this instrumental regression are presented in Table 3. With this forecast of future attendance, we model:

att $_{\mathrm{t}}=\mathrm{b}_{0}+\mathrm{b}_{1}$ att $_{\mathrm{t}-1}+\mathrm{b}_{2}$ fatt $_{\mathrm{t}+1}+\mathrm{b}_{3} \mathrm{E}_{\mathrm{d}, \mathrm{t}-1}\left(1-\mathrm{TOOBIG}_{\mathrm{t}}\right)+\mathrm{b}_{4}$ TOOBIG $_{\mathrm{t}}+\mathrm{b}_{5}$ WINPCT $_{\mathrm{t}}+\mathrm{e}_{\mathrm{t}}$

where fatt $t+1$ is the forecast of attendance in period $t+1$ given information available at time $t$, and $e_{t}$ is a stochastic noise term that captures non-systematic variations in attendance. Now, given the potential for binding capacity constraints, we will not always observe the quantity of tickets demanded. That is, we actually only observe (Tobin):

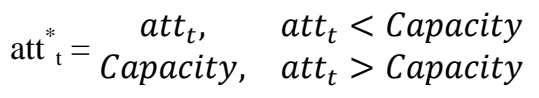

We define $\hat{e}=a t t_{t}-\hat{b_{0}}-\hat{b_{1}} a t t_{t-1}-\hat{b_{2}} f_{a t t_{t+1}}-\hat{b_{3}} E_{d, t-1}\left(1-\right.$ TOOBIG $\left._{t}\right)-\hat{b_{4}} T O O B I G_{t}-\hat{b_{5}}$ WINPCT $_{t}$ 
This allows us to state the maximum likelihood function as

$L=\Pi\left(1-F\left(\right.\right.$ Capacity $\left.\left.-a \hat{t} t_{t}\right)\right) \prod f\left(\hat{e}_{t}: a t t_{t}>\right.$ Capacity $)$,

where $\mathrm{F}$ is the cumulative density function of a standard normal and $f(:)$ is the probability density function of a conditional standard normal random variable.

Estimation results of the TOBIT model are presented in Table 4. The independent variables have the theoretically expected sign and are statistically significant at any reasonable level of tolerance. In particular, it appears that the dynamic interaction between fans and teams is being captured by the parameter on the lagged Elasticity of Demand. That is, teams that do not have excess capacity tend to follow periods of constrained ticket demand by lowering ticket price and adding to stadium capacity. When Elasticity of Demand is less than 1, teams tend not to add to stadium capacity and increase ticket prices.

Table 4: Tobit Estimates of Equation 7

\begin{tabular}{|l|c|c|}
\hline \multicolumn{1}{|c|}{ Variable } & Estimate & T-statistic \\
\hline (Intercept) & 0 & NA \\
\hline $\mathrm{I}(100 *$ I_tooBig) & -394.41299 & -4.331 \\
\hline $\mathrm{I}(100 * \mathrm{Ed})$ & 283.61242 & 2.989 \\
\hline ATT $_{\mathrm{t}+1}$ & 0.25791 & 6.864 \\
\hline ATT $_{\mathrm{t}-1}$ & 0.79235 & 24.955 \\
\hline WINPCT & 26.02362 & 3.11 \\
\hline Log(scale $)$ & 10.09671 & 213.369 \\
\hline
\end{tabular}

As expected, the coefficients on past ATT ${ }_{\mathrm{t}-1}$ and future attendance $\mathrm{ATT}_{\mathrm{t}+1}$ are positive and significant. Past attendance contributes 0.79 on current attendance while expected future attendance contributes 0.26 on current attendance. This is consistent with rational addiction theory, which supports the notion that NFL fans display characteristics of rational addiction. This implies that as past and expected future attendance rise, attendance in the current season rises as well.

The coefficient for the team's winning percentage is also positive and significant. This is in accordance other research, since nearly all studies that examine the demand for attendance at professional sporting events include some measure of team performance in the equation, which is usually found to positively affect attendance. Welki and Zlatoper (1994) find that the home team record is a significant factor in determining game day attendance. Berri, Schmidt, and Brook (2004) also find that team performance is an important factor in determining attendance with wins, playoff wins, and championships all turning out to be significant and positive in their analysis of attendance at NBA games. This suggests that a team that wins more games tends to attract more fans.

Model results also suggest that teams operating with greater than 5\% excessive capacity tend to experience a reduction in attendance of 39,441 fans per season. This is because teams with excessive capacity beyond $5 \%$ will absorb the coefficient on TOOBIG. While we anticipate that teams in this situation maximizing profits are still operating around unitary elasticity of demand, we cannot accurately measure this elasticity of demand by using stadium capacity.

Teams with excessive capacity below 5\% allow us to accurately proxy the elasticity of demand and the teams interaction with fans through pricing. Our model results suggest that a $1 \%$ rise in the previous year's ownprice elasticity of demand results in 283.61 more fan attendance in the current year. Again, this is consistent with team profit maximizing behavior. A large elasticity of demand in the previous year signals the team experienced a stadium capacity constraint or inadvertently charged too high a price to maximize profits. Thus, we anticipate the team will reduce real ticket prices and/or expand stadium capacity in the current year to increase profits. The corollary is that a $1 \%$ decline in the previous year's own-price elasticity of demand results in 283.61 fewer fans in the current year. This is because if own-price elasticity is below 1 the previous year, the profit maximizing team will raise ticket prices and increase profits. This higher price results in fewer ticket sales holding everything else constant. 
The variable $\log (\mathrm{Scale})$ refers to the dependent variable's estimated standard error. We directly measure this parameter in the maximum likelihood setting. This suggests a standard error in our ticket demand model of 24,343 tickets for a season. We anticipate that $95 \%$ of the time a team's actual season ticket demand will be within 97,372 of our fitted model estimate.

\section{CONCLUSIONS}

This study has attempted to answer questions about attendance at National Football League games by estimating the demand for tickets to these games and examining fan behavior. In the past, rational addiction theory, pioneered by Becker and Murphy (1988), has been used to explain the demand for habit-forming goods. Rational addiction theory suggests that people make choices according to their consistent utility maximization plan, implying that past and expected future consumption of a habit-forming good would likely impact the present consumption of that good for addicted consumers. The purpose of this paper was to test for characteristics of rational addiction among fans of the National Football League.

While there have been many studies that have attempted to explain attendance at various sporting events, there have been relatively few attendance studies that have examined the NFL. There have also been a number of studies that have tested rational addiction theory, but none of them have examined this theory in the context of professional football. This paper has summarized the main findings of previous research and extended it by combining the theories found in the two bodies of literature.

Previous work on attendance provides various models with many variables that have been hypothesized to have an impact on attendance at professional sporting events. These variables include, but are not limited to, teamspecific variables, such as winning percentage and the number of marquis players on a given team's roster, and league-specific variables, such as the incidence of strikes and measures of competitive balance. Also, key economic demand determinants, such as ticket price and income, are included in traditional attendance demand models. The innovation of this research is the inclusion of past and future attendance in the demand equation. This comes from the derivation of the demand curve for habit-forming goods that is outlined in detail in the appendix. Testing for significance of these two variables in the demand function explores the possibility of habit-formation among the consumers who are, in this case, NFL fans.

To test the rational addiction model empirically, data were collected for the 1985 through $2002 \mathrm{NFL}$ seasons. The data set is a pooled set comprised of statistics from each NFL team for each season that is played during the period included in the study. The results are very consistent among the models, showing the same variables to be significant with uniformity in the signs and magnitudes of coefficients. Past and future attendance, winning percentage, stadium age, and strike years were found to be significant factors in explaining attendance at NFL games. These findings are consistent with the theory. However, there are some caveats that merit discussion.

First of all, NFL games sell out on a regular basis, which creates econometric difficulties when one is trying to estimate demand. A simultaneous Tobit estimation might be more appropriate with the truncated dependent variable. Also, to better test for habit formation, it would be beneficial to know whether or not the same people are attending games. Such data are not available for attendance at NFL games due to the lack of panel data. These problems motivate the suggestions for future research.

\section{FUTURE RESEARCH}

It would be interesting to employ the rational addiction model to test television viewership in the NFL, using data from Nielsen ratings to test for habit-formation among fans that watch professional football from their own homes. This would remedy the problem that excess attendance demand may cause, since there is not a fixed stadium capacity when it comes to television broadcasts. The excess demand, evidenced by sellouts, causes a truncated dependent variable. This can cause econometric problems if the model is not estimated correctly. The econometric problems that arise from improper estimation include nonsensical predicted values, biased regression coefficients, error terms that are not normally distributed, and heteroscedasticity. 
Another benefit of using Nielsen ratings is that viewership could be tracked to see if it is indeed the same households that are tuning in game after game, which would provide more compelling evidence for habit-formation. Furthermore, the utility function in the optimization problem is assumed to be quadratic. This does not model rational addicts correctly since it implies that if there is any deviation from the steady state of consumption, the addict will either quit consuming altogether or increase consumption infinitely. This is not the case according to rational addiction theory, which suggests that there are actually several steady states of consumption to which addicts can move. Using a Cobb-Douglas function or some other functional form would provide innovation in rational addiction literature. However, using these functions in the optimization problem may make it impossible to solve. These are simply suggestions to keep in mind for further research that is beyond the scope of the current study.

\section{IMPLICATIONS}

This research provides some insights into the habit-formation aspects of the demand for NFL football that have not been included in earlier studies. Calculating the elasticity of demand with respect to winning percentage provides one interesting insight. When these elasticities are calculated, the impact of winning percentage on attendance is not found to be as significant as one might expect. Using the basic linear FE2SLS regression model, the elasticity of demand with respect to winning percentage for the entire league was found to be 0.03 . Also, the sample was broken down by team for Denver, Cincinnati, Tampa Bay, and Dallas and the elasticities were calculated for the individual teams. Again, the elasticity of demand with respect was found to be approximately 0.03 for each one of the teams for which it was calculated. This implies that for every one percent increase in winning percentage, attendance increases by 0.03 percent. For the four teams tested, a rise in attendance of that magnitude translates into between 12,700 and 17,500 more fans attending games in a given year.

This study has some important implications, especially for those that set ticket prices for the NFL. Researchers in the field of sports economics have been puzzled by the fact that analyses of attendance demand at professional sporting events consistently find that tickets for games are priced in the elastic range of the demand curve. This is contradictory to microeconomic theories that state that optimal prices, which are those that maximize profits, are set in the inelastic portion of the demand curve. Estimates of price elasticity in studies by Noll (1974) and Fort (2003) suggest that prices are not set at this optimal point. Allowing for habit-formation provides a possible explanation for this puzzling phenomenon. Owners may be aware of the effect that habitual behavior has on demand and they may price tickets accordingly, hoping to increase current attendance in order to increase their future profits by getting more people "hooked" on the sport. This study supports such a notion and suggests that by continuing to price in the elastic portion of the demand curve, the NFL can hope to increase the demand for attendance at their games in the long run.

In conclusion, this study provides support for the rational addiction model for the consumption behavior of NFL fans. The results suggest that the consumption of NFL games, at least in attendance at NFL games, is indeed habit forming. This study provides a starting point for the examination of habit-formation in professional sports.

\section{AUTHOR INFORMATION}

Erin Hutchinson (was Spenner; now married) is a Senior Associate at Duff \& Phelps and part of the Transfer Pricing practice. At Duff \& Phelps, Erin is involved in intangible property valuations and transfer pricing analysis and documentation for multinational corporations. She is also responsible for economic and fiscal impact studies, and assists with transfer pricing controversy issues. Erin graduated summa cum laude with a B.A. in Economics from Colorado College and will be pursuing a Ph.D. in Economics at the University of Colorado, Boulder.

Aju Fenn holds the John L. Knight Chair of Free Enterprise at Colorado College. He is also the Chair of the Economics and Business Department. He teaches Mathematical Economics, Sports Economics and Econometrics. He conducts research in Sports Economics and in the Economics of Addiction. He holds a Ph.D. and M.S. from Iowa State University in Economics. He earned his B.A. from the College of Wooster and his B.Sc. From Calcutta University - St. Xavier's College. 
John Crooker is the Associate Dean of the Harmon College of Business Administration at Central Missouri State University. He is an Associate Professor in the Department of Economics and Finance there. He earned his Ph.D. from Iowa State University and his undergraduate degree from Central Missouri State University. He conducts research in Resource and Environmental Economics and Sports Economics.

\section{REFERENCES}

1. $\quad$ Ahn, Seung, and Young Lee. "Life-Cycle Demand for Major League Baseball." Working Paper (2003).

2. $\quad$ Baimbridge, Mark. "Match attendance at Euro 96: Was the crowd waving or drowning?" Applied Economics Letters 4 (1997): 555-558.

3. $\quad$ Becker, Gary, Michael Grossman, and Kevin Murphy. "An Empirical Analysis of Cigarette Addiction." The American Economic Review 84, no. 3 (1994): 396-418.

4. Becker, Gary S., and Kevin M. Murphy. "A Theory of Rational Addiction." Journal of Political Economy 6, no. 4 (1988): 675-700.

5. Berri, David, Martin Schmidt, and Stacey Brook. "Stars at the Gate: The Impact of Star Power on NBA Gate Revenues. " The Journal of Sports Economics 5, no. 1 (2004): 33-50.

6. Boyd, Thomas, and Timothy Krehbiel. "Promotion Timing in Major League Baseball and the Stacking Effects of Factors That Increase Game Attractiveness. " Sport Marketing Quarterly 12, no.3 (2003): 173184

7. Burdekin, Richard, and Todd Idson. "Customer preferences, attendance, and the racial structure of professional basketball teams." Applied Economics 23 (1991): 179-186.

8. $\quad$ Byers, Peel, and Thomas. "Habit and Long Memory in Attendance Demand: The Case of Football Support. " Working Paper (2000).

9. Carroll, Bob. Total Football II: The Encyclopedia of the National Football League. New York: Harper Collins Publishers, Inc., 1999.

10. Chaloupka, Frank. "An economic analysis of addictive behavior: The case of cigarette smoking." Ph.D. Dissertation. City University of New York, 1988.

11. Chaloupka, Frank. "Rational Addictive Behavior and Cigarette Smoking." Journal of Political Economy 99, no. 4 (1991): 722-742.

12. DeSchriver, Timothy, and Paul Jensen. "Determinants of Spectator Attendance at NCAA Division II Football Contests." Journal of Sport Management 16 (2002): 311-330.

13. $\quad$ Dobson, and Goddard. "The demand for professional league football in England and Wales, 1925-1992." The Statistician 44, no. 2 (1995): 259-277.

14. Downward, Paul and Alistair Dawson. The Economics of Professional Team Sports. London: Routledge, 2000.

15. Fenn, Aju, Frances Antonovitz, and John Schroeter. "Cigarettes and addiction information: new evidence in support of the rational addiction model." Economics Letters (2001): 39-45.

16. Fenn, Aju. "The impact of addiction information on cigarette consumption." Ph.D. Dissertation. Iowa State University, 1998.

17. $\quad$ Fort, Rodney. "Sports Business Data Pages." available from http://users.pullman.com/rodfort/SportsBusiness/BizFrame.htm, accessed February 4, 2004.

18. Gerdy, John R. Sports: The All-American Addiction. Jackson, Mississippi: University Press of Mississippi, 2002.

19. Greene, William H. Econometric Analysis. Third Edition. Upper Saddle River, New Jersey: Prentice Hall. 1997.

20. Grossman, Michael. "The Economic Analysis of Addictive Behavior." The Economics and Prevention of Alcohol Related Problems (1993).

21. Hall, Stephen. "Satellite television and football attendance: the not so super effect. " Applied Economics Letters 11, no. 2 (2004): 123-126.

22. Horrow, Rick. "The NFL Juggernaut at Postseason, Part I," available from http://cbs.sportsline.com/general/story/7003559, accessed February 1, 2004.

23. The National Football League. The Official National Football League Record and Fact Book. New York: The National Football League, 1983-2002. 
24. Howard, Dennis, and John Crompton. "An Empirical Review of the Stadium Novelty Effect." Sport Marketing Quarterly 12, no. 2 (2003): 111-116.

25. Kahane, Leo, and Stephen Schmanske. "Team roster turnover and attendance in Major League Baseball." Applied Economics 29 (1997): 425-431.

26. Marshall, Alfred. Principles of Economics. Eighth Edition. London: The Macmillan Company, 1920.

27. McDonald, Mark, and Daniel Rascher. "Does Bat Day Make Cents? The effect of promotions on the demand for Major League Baseball." Journal Of Sport Management 14 (2000): 8-27.

28. Noll, Roger. "Attendance and Price Setting." In Government and the Sports Business. Washington, D.C.: The Brookings Institution, 1974, 115-157.

29. Peel, and Thomas. "Outcome uncertainty and the demand for football: An analysis of match attendances in the English Football League." Scottish Journal of Political Economy 35, no. 3 (1988): 242-249.

30. Price, Donald, and Kabir Sen. "The Demand for Game Day Attendance in College Football: An Analysis of the 1997 Division 1-A Season." Managerial and Decision Economics 24, no.1 (2003): 35-47.

31. Quirk, James, and Rodney Fort. Pay Dirt: The Business of Professional Team Sports. Princeton, New Jersey: Princeton University Press, 1992.

32. Rivers, Dominic, and Timothy DeSchriver. "Star Players, Payroll Distribution, and Major League Baseball Attendance." Sport Marketing Quarterly 11, no. 3 (2002): 164-173.

33. Schmidt, Martin, and David Berri. "Competitive Balance and Attendance: The Case of Major League Baseball.” Journal of Sports Economics 2, no. 2 (2001):145-167.

34. Schmidt, Martin and David Berri. "The impact of the 1981 and 1994-1995 strikes on Major League Baseball Attendance: a time-series analysis." Applied Economics 34, no. 4 (2002): 471-479.

35. Szymanski, Stefan. "Income Inequality, Competitive Balance and the Attractiveness of Team Sports: Some Evidence and a Natural Experiment from English Soccer." Economic Journal 111, no. 469 (2001).

36. Welki, Andrew, and Thomas Zlatoper. "US Professional Football: The Demand for Game-Day Attendance in 1991." Managerial and Decision Economics 15 (1994): 489-495.

37. Zhang, Pease, Hui, and Michaud. "Variables affecting spectator decisions to attend NBA games." Sport Marketing Quarterly 4, no. 4 (1995): 29-39.

\section{WEB PAGE REFERENCES}

1. $\quad$ "Major League Baseball Teams." available from http://www.mlb/com/teams, accessed October 4, 2003.

2. $\quad$ "NBA Teams." available from http://www.nba.com/teams, accessed October 4, 2003.

3. $\quad$ "NFL Teams." available from http://www.nfl.com/teams, accessed October 4, 2003.

4. $\quad$ "NHL Teams." available from http://www.nhl.com/teams, accessed October 4, 2003.

5. "Pro Bowl Rosters." available from http://pro-football-reference.com/misc/pbindex.htm, accessed October 4, 2003.

6. The Bureau of Economic Analysis. "Regional Economic Accounts: Metropolitan Statistical Area Per Capita Personal Income." available from http://bea.gov/bea/regional/reis/, accessed October 4, 2003.

7. Tomasch, Kenn. "NFL Attendance. " available from http://kenn.com/sports/football/nfl/nfl_lg attendance.html, accessed March 9, 2004.

8. $\quad$ U.S. Department of Labor, Bureau of Labor Statistics. "Consumer Price Index." Available from http://www.bls.gov/cpi/, accessed February 1, 2004. 


\section{APPENDIX}

The purpose of this Appendix is to derive the demand function for an addictive good. This will follow the derivation that was already outlined but will go over the details that were not included in the text.

The derivation depends on the assumed utility function for a rational agent and the equation for the addictive stock that a habit-forming good accumulates.

Utility Function:

$U_{t}=U\left(Y_{t}, C_{t}, A_{t}, e_{t}\right)$

Addictive Stock:

$$
A_{t}=(1-\delta) C_{t-1}+(1-\delta) A_{t-1}
$$

It is assumed that the rate of decay of the addictive stock is $100 \%$, which implies that $\delta$ is equal to one in the coefficient of the $A_{t-1}$ term. This leaves the following equation for the addictive stock constraint:

$$
A_{t}=(1-\delta) C_{t-1}
$$

Now, the addictive stock constraint can be substituted into the utility function, leaving a function that represents utility in terms of consumption of the addictive good and consumption of all other goods:

$$
U_{t}=U\left(Y_{t}, C_{t},(1-\delta) C_{t-1}, e_{t}\right)
$$

Assuming that an agent lives to time $T$ and discounts their utility according to the market rate of interest, $r$, lifetime utility, $U$, can be represented as follows, where $\beta$ represents the discount factor $\frac{1}{1+r}$ :

$U=\sum_{t=1}^{T} \beta^{t-1}\left(Y_{t}, C_{t},(1-\delta) C_{t-1}, e_{t}\right)$

The lifetime budget constraint is represented as follows, where $W$ represents the present value of lifetime wealth, $Y_{t}$ is the numeraire good, $P_{t}$ is the price of the addictive good in time $t$ and $C_{t}$ is the quantity consumed of the addictive good in time $t$ and $\beta$ is again the consumer's discount factor $\frac{1}{1+r}$ :

$W=\sum_{t=1}^{T} \beta^{t-1}\left(Y_{t}+P_{t} * C_{t}\right)$

\section{Solving for First Order Conditions}

The objective is to maximize lifetime utility, $U$, subject to the budget constraint, $W$. It is necessary to set up a simple Lagrangian optimization problem, as follows:

$$
L=\sum_{t=1}^{T} \beta^{t-1} U\left(Y_{t}, C_{t},(1-\delta) C_{t-1}, e_{t}\right)+\lambda\left[W-\sum_{t=1}^{T} \beta^{t-1}\left(Y_{t}+P_{t} * C_{t}\right)\right]
$$


The first step is to take a partial derivative of equation a.7 with respect to $Y_{t}$ and set it equal to zero, yielding the following:

$$
\frac{\partial L}{\partial Y_{t}}=\beta^{t-1} U_{Y_{t}}\left(Y_{t}, C_{t},(1-\delta) C_{t-1}, e_{t}\right)-\lambda \beta^{t-1}=0
$$

Upon simplification, the following first order condition is obtained:

$U_{Y_{t}}\left(Y_{t}, C_{t},(1-\delta) C_{t-1}, e_{t}\right)=\lambda$

The next step involves taking the partial derivative of equation a. 7 with respect to $C_{t}$ and setting it equal to zero. However, the Lagrangian problem from equation a.7 must be expanded due to the fact that the variable of interest, $C_{t}$, is present in the summation not only at time $t$, but also at time $t+1$. This makes it necessary to have four separate terms in the Lagrangian equation for four distinct scenarios. A term is needed for time 1 to $t-1$, plus a term for time $t$, another term for time $t+1$, and a final term for time $t+2$ to $T$ in order to explain the four possibilities and isolate the scenarios at time $t$ and time $t+1$, which will be the times that $C_{t}$ remains in the equation. The resulting Lagrangian is presented in equation a.10:

$$
\begin{aligned}
& L=\sum_{t=1}^{t-1} \beta^{t-1} U\left(Y_{t}, C_{t},(1-\delta) C_{t-1}, e_{t}\right)+\beta^{t-1} U\left(Y_{t}, C_{t},(1-\delta) C_{t-1}, e_{t}\right) \\
& +\beta^{t} U\left(Y_{t+1}, C_{t+1},(1-\delta) C_{t}, e_{t+1}\right)+\sum_{t=t+2}^{T} \beta^{t-1} U\left(Y_{t}, C_{t},(1-\delta) C_{t-1}, e_{t}\right) \\
& +\lambda\left[W-\sum_{t=1}^{T} \beta^{t-1}\left(Y_{t}+P_{t} * C_{t}\right)\right]
\end{aligned}
$$

The partial derivative with respect to $C_{t}$ can now be taken, producing the following equation, which has been set equal to zero:

$$
\begin{aligned}
& \frac{\partial L}{\partial C_{t}}=\beta^{t-1} U_{C_{t}}\left(Y_{t}, C_{t},(1-\delta) C_{t-1}, e_{t}\right) \\
& +\beta^{t} U_{C_{t}}\left(Y_{t+1}, C_{t+1},(1-\delta) C_{t}, e_{t+1}\right) *(1-\delta)-\lambda \beta^{t-1} P_{t}=0
\end{aligned}
$$

Some simplification yields the following, which is the second of the first order conditions:

$$
\begin{aligned}
& U_{C_{t}}\left(Y_{t}, C_{t},(1-\delta) C_{t-1}, e_{t}\right)+\beta U_{C_{t}}\left(Y_{t+1}, C_{t+1},(1-\delta) C_{t}, e_{t+1}\right) *(1-\delta) \\
& =\lambda P_{t}
\end{aligned}
$$

\section{Deriving the Demand Function}

In keeping with Becker et al. (1994) ${ }^{5}$ and Fenn (1998), ${ }^{6}$ the utility function is assumed to be quadratic in the current period's consumption of the addictive good, the composite good, the addictive stock, and the other

\footnotetext{
${ }^{5}$ Gary Becker, Michael Grossman, and Kevin Murphy, “An Empirical Analysis of Cigarette Addiction,” The American Economic Review, Volume 84, Number 3, 1994: 396-418.

${ }^{6}$ Aju Fenn, "The impact of addiction information on cigarette consumption," Ph.D. Dissertation, Iowa State University, 1998.
} 
unobservable events that impact utility. These variables are denoted by $C_{t}, Y_{t}, A_{t}$, and $e_{t}$, respectively. Just as before, a substitution is made for $A_{t}$, according to the addictive stock constraint from equation a.3. The result is the following utility function, first outlined in Becker and Murphy (1988):

$U_{t}=U_{1} C_{t}+U_{2}(1-\delta) C_{t-1}+U_{Y} Y_{t}+U_{e} e_{t}+\frac{U_{11}}{2} C_{t}^{2}+\frac{U_{22}}{2}(1-\delta)^{2} C_{t-1}^{2}$

$+\frac{U_{Y Y}}{2} Y_{t}^{2}+\frac{U_{e e}}{2} e_{t}^{2}+U_{12} C_{t}(1-\delta) C_{t-1}+U_{1 Y} C_{t} Y_{t}+U_{1 e} C_{t} e_{t}$

$+U_{2 Y}(1-\delta) C_{t-1} Y_{t}+U_{2 e}(1-\delta) C_{t-1} e_{t}+U_{Y e} Y_{t} e_{t}$

Taking the partial derivative of the exact utility function in equation a.13 with respect to $\mathrm{Y}_{\mathrm{t}}$ and setting it equal to $\lambda$ produces the exact form of the first order condition, given in equation a.14:

$\frac{\partial U_{t}}{\partial Y_{t}}=U_{Y}+U_{Y Y} Y_{t}+U_{1 Y} C_{t}+U_{2 Y}(1-\delta) C_{t-1}+U_{Y e} e_{t}=\lambda$

Now, equation a.14 can be solved for $\mathrm{Y}_{\mathrm{t}}$ :

$Y_{t}=\frac{\lambda-U_{Y}-U_{1 Y} C_{t}-U_{2 Y}(1-\delta) C_{t-1}-U_{Y e} e_{t}}{U_{Y Y}}$

Similarly, taking the partial derivative of the exact utility function with respect to $\mathrm{Ct}$, and setting it equal to $\lambda$ can obtain the exact form of the second of the first order conditions.

$\left[U_{1}+U_{11} C_{t}+U_{12}(1-\delta) C_{t-1}+U_{1 Y} Y_{t}+U_{1 e} e_{t}\right]+\beta\left[U_{2}(1-\delta)\right.$

$\left.+U_{22}(1-\delta)^{2} C_{t}+U_{12}(1-\delta) C_{t-1}+U_{2 Y}(1-\delta) Y_{t+1}+U_{2 e}(1-\delta) e_{t+1}\right]$

$=\lambda P_{t}$

Next, equation a.15 will be used to substitute for $\mathrm{Y}_{\mathrm{t}}$ and $\mathrm{Y}_{\mathrm{t}+1}$ in equation a.16 in order to get the marginal utility function for the addictive good completely in terms of $\mathrm{C}_{\mathrm{t}}$ and exogenous variables:

$$
\begin{aligned}
& {\left[U_{1}+U_{11} C_{t}+U_{12}(1-\delta) C_{t-1}+U_{1 Y}\left[\frac{\lambda-U_{Y}-U_{1 Y} C_{t}-U_{2 Y}(1-\delta) C_{t-1}-U_{Y e} e_{t}}{U_{Y Y}}\right]\right.} \\
& \left.+U_{1 e} e_{t}\right]+\beta\left[U_{2}(1-\delta)+U_{22}(1-\delta)^{2} C_{t}+U_{12}(1-\delta) C_{t-1}\right. \\
& \left.+U_{2 Y}(1-\delta)\left[\frac{\lambda-U_{Y}-U_{1 Y} C_{t+1}-U_{2 Y}(1-\delta) C_{t}-U_{Y e} e_{t+1}}{U_{Y Y}}\right]+U_{2 e}(1-\delta) e_{t+1}\right] \\
& =\lambda P_{t}
\end{aligned}
$$

Now, the function can be solved for $\mathrm{C}_{\mathrm{t}}$ : 


$$
\begin{aligned}
& U_{11} C_{t}-\frac{U_{1 Y}^{2} C_{t}}{U_{Y Y}}+\beta U_{22}(1-\delta)^{2} C_{t}-\frac{\beta U_{2 Y}^{2}(1-\delta)^{2} C_{t}}{U_{Y Y}} \\
& =\lambda P_{t}-U_{1}-U_{12}(1-\delta) C_{t-1}-\frac{U_{1 Y} \lambda}{U_{Y Y}}+\frac{U_{1 Y} U_{Y}}{U_{Y Y}}+\frac{U_{1 Y} U_{2 Y}(1-\delta) C_{t-1}}{U_{Y Y}} \\
& +\frac{U_{1 Y} U_{Y e} e_{t}}{U_{Y Y}}-U_{1 e} e_{t}-\beta U_{2}(1-\delta)-\beta U_{12}(1-\delta) C_{t-1}-\beta U_{2 Y}(1-\delta) \lambda \\
& +\frac{\beta U_{2 Y}(1-\delta) U_{Y}}{U_{Y Y}}+\frac{\beta U_{2 Y}(1-\delta) U_{1 Y} C_{t-1}}{U_{Y Y}}+\frac{\beta U_{2 Y}(1-\delta) U_{Y e} e_{t+1}}{U_{Y Y}} \\
& -\beta U_{2 e}(1-\delta) e_{t+1}
\end{aligned}
$$

In the left-hand side of the equation, $C_{t}$ can be factored out. Let the remaining pieces be equal to $\Omega$

$$
\begin{aligned}
& C_{t}\left[U_{11}-\frac{U_{1 Y}^{2}}{U_{Y Y}}+\beta U_{22}(1-\delta)^{2}-\frac{\beta U_{2 Y}^{2}(1-\delta)^{2}}{U_{Y Y}}\right]=P_{t}-U_{1}-U_{12}(1-\delta) C_{t-1} \\
& -\frac{U_{1 Y} \lambda}{U_{Y Y}}+\frac{U_{1 Y} U_{Y}}{U_{Y Y}}+\frac{U_{1 Y} U_{2 Y}(1-\delta) C_{t-1}}{U_{Y Y}}+\frac{U_{1 Y} U_{Y e} e_{t}}{U_{Y Y}}-U_{1 e} e_{t}-\beta U_{2}(1-\delta) \\
& -\beta U_{12}(1-\delta) C_{t-1}-\beta U_{2 Y}(1-\delta) \lambda+\frac{\beta U_{2 Y}(1-\delta) U_{Y}}{U_{Y Y}}+\frac{\beta U_{2 Y}(1-\delta) U_{1 Y} C_{t-1}}{U_{Y Y}} \\
& +\frac{\beta U_{2 Y}(1-\delta) U_{Y e} e_{t+1}}{U_{Y Y}}-\beta U_{2 e}(1-\delta) e_{t+1}
\end{aligned}
$$

$$
\Omega=\left[U_{11}-\frac{U_{1 Y}^{2}}{U_{Y Y}}+\beta U_{22}(1-\delta)^{2}-\frac{\beta U_{2 Y}^{2}(1-\delta)^{2}}{U_{Y Y}}\right]
$$

Both sides of the equation will then be divided by $\Omega$, leaving $C_{t}$ alone on the left-hand side. The remaining terms on the right-hand side can now be reduced and terms can be collected to find coefficients for the intercept, $C_{t}$ ${ }_{1}, C_{t+1}, P_{t}, e_{t}$, and $e_{t+1}$ :

$$
\begin{aligned}
& C_{t}=\frac{\left[-U_{1}-U_{1 Y} \frac{\left(\lambda-U_{Y}\right)}{U_{Y Y}}-\beta U_{2}(1-\delta)-\beta U_{2 Y} \frac{(1-\delta)\left(\lambda-U_{Y}\right)}{U_{Y Y}}\right]}{\Omega} \\
& +\frac{1}{\Omega}\left[-U_{12}(1-\delta)+\frac{U_{1 Y} U_{2 Y}(1-\delta)}{U_{Y Y}}\right]\left(C_{t-1}\right)+\frac{1}{\Omega}\left[-\beta U_{12}(1-\delta)+\frac{\beta U_{1 Y} U_{2 Y}(1-\delta)}{U_{Y Y}}\right]\left(C_{t+1}\right) \\
& +\frac{\lambda}{\Omega}\left(P_{t}\right)+\frac{1}{\Omega}\left[\frac{U_{1 Y} U_{1 e}}{U_{Y Y}}-U_{1 e}\right]\left(e_{t}\right)+\frac{1}{\Omega}\left[\frac{\beta U_{2 Y} U_{Y e}(1-\delta)}{U_{Y Y}}-\beta U_{2 e}(1-\delta)\right]\left(e_{t+1}\right)
\end{aligned}
$$


The demand equation for the addictive good, $C_{t}$, can easily be seen if the terms that make up the coefficients are renamed as $\alpha$ terms:

$\alpha_{0}=\frac{\left[-U_{1}-U_{1 Y} \frac{\left(\lambda-U_{Y}\right)}{U_{Y Y}}-\beta U_{2}(1-\delta)-\beta U_{2 Y} \frac{(1-\delta)\left(\lambda-U_{Y}\right)}{U_{Y Y}}\right]}{\Omega}$

$\alpha_{1}=\frac{1}{\Omega}\left[-U_{12}(1-\delta)+\frac{U_{1 Y} U_{2 Y}(1-\delta)}{U_{Y Y}}\right]$

$\alpha_{2}=\frac{1}{\Omega}\left[-\beta U_{12}(1-\delta)+\frac{\beta U_{1 Y} U_{2 Y}(1-\delta)}{U_{Y Y}}\right]$

$\alpha_{3}=\frac{\lambda}{\Omega}$

$\alpha_{4}=\frac{1}{\Omega}\left[\frac{U_{1 Y} U_{1 e}}{U_{Y Y}}-U_{1 e}\right]$

$\alpha_{5}=\frac{1}{\Omega}\left[\frac{\beta U_{2 Y} U_{Y e}(1-\delta)}{U_{Y Y}}-\beta U_{2 e}(1-\delta)\right]$

Thus, the demand equation is as follows:

$C_{t}=\alpha_{0}+\alpha_{1} C_{t-1}+\alpha_{2} C_{t+1}+\alpha_{3} P_{t}+\alpha_{4} e_{t}+\alpha_{5} e_{t+1}$

Notice that the current period's price is included in the demand for the addictive good, as well as past and expected future consumption of the good. This is the key to the rational addiction model. 
NOTES 